\section{Turning Point-Rethinking Violence: A Youth Violence Reduction Intervention}

\section{Kamela K Scott ${ }^{1 *}$, Angela I Canto ${ }^{2 *}$, Shannon M Smith ${ }^{2}$ and Joseph J Tepas ${ }^{1}$}

${ }^{1}$ Department of Surgery, University of Florida College of Medicine Jacksonville, Florida, USA

${ }^{2}$ Educational Psychology and Learning Systems, The Florida State University, Tallahassee, Florida, USA

\begin{abstract}
Objectives: In response to a significant increase in adolescent violence, a multi-dimensional, multi-agency program involving at-risk adolescents and their parents was implemented, housed at the urban Level One Trauma Center of a southeastern hospital. "Turning Point: Re-Thinking Violence," (TPRV) was initiated in 1999 as a focused 14-hour alternative to the standard sentence of 100 hours of "community service" for first time violent juvenile offenders. Juvenile participants attended a total of six group sessions which included: trauma experience activities; a victim impact panel; a processing and psycho educational group focused on anger management, conflict resolution, and communication skills; community networking; and a program graduation. This study analyzes the long-term effect both in rates of Violence Recidivism (VR) and program efficiency as indicated by maintained therapeutic effect.

Methods: VR of TPRV consenting program participants $(\mathrm{N}=115)$ during seven years of TPRV was compared to the initial cohort sentenced to the "traditional" community service. TPRV participants were then stratified by year of program entry, and compared among themselves.

Results: For the six year duration of TPRV, the VR rate still remains significantly below that which was reported in the index group. Stratified annual analysis demonstrates a statistically significant decrease in VR as TPRV has evolved.

Conclusions: These data suggest that TPRV is an efficient and effective violence intervention program as compared to traditional

*Corresponding author: Angela Canto, Ph.D., Educational Psychology and Learning Systems ,The Florida State University, 3210 Stone Building, PO Box 3064453, Tallahassee, FL 32306-4453, USA, Tel: 8506449440; Fax: 8506448776; E-mail: acanto@fsu.edu
\end{abstract}

Kamela Scott, Ph.D., Department of Surgery, University of Florida Health Science Center - Jacksonville, 655 W 8th St, Jacksonville, FL 32209, USA, Tel: 9042443352; Fax: 9042444687; E-mail: kamela.scott@jax.ufl.edu

Citation: Scott KK, Canto AI, Smith SM, Tepas JJ (2014) Turning Point-Rethinking Violence: A Youth Violence Reduction Intervention. J Emerg Med Trauma Surg Care 2: 004

Received: September 26, 2014; Accepted: January 05, 2014; Published: January 19, 2014 sentencing options for first-time adolescent violent offenders and that the treatment effect of TPRV is sustained over time and is judged to be a successful strategy for addressing the epidemic of adolescent violence.

Keywords: Adolescent, Recidivism, Sustainability, Violence

Prevention that Works: Effects of a Focused, Comprehensive Adolescent Violence Intervention Program

Juvenile violent crime is a grave problem in the United States. The sheer volume alone is placing significant burdens upon local, state and national legal systems. According to the "Crime in the United States 2012" report [1], juveniles (under age 18) were arrested for the following crimes nationally in 2012: murder or non-negligent manslaughter, 560; forcible rape, 1,954; robbery, 16,563; weapons offenses, 18,856; aggravated assault, 28,160; and other assaults, 132,198 . Juveniles accounted for $10.8 \%$ of all violent crimes committed in 2012 [1]. In Florida, during FY 2010-11 the Department of Juvenile Justice [2] handled 109,813 referrals for 66,934 juveniles, with burglary and aggravated assault as the most common felony referrals (13,323 juveniles) and theft and assault as the most common misdemeanor referrals (22,395 juveniles). Further, according to Florida's Department of Juvenile Justice [2], approximately one-third of referred juveniles were female (20,593 females and 46,341 males).

Although there was a decline of $37.2 \%$ in juvenile arrests from 2003 to 2012 [1], juvenile violence continues to strain the legal system, detainment facilities, and local medical centers. Further, social services and healthcare delivery systems, in particular, are incurring a tremendous fiscal burden. Studies have shown consistently over the past fifteen years, violent crime has cost Americans approximately $\$ 1.7$ trillion annually when direct and indirect costs of crime (e.g., property destruction, medical services, operation of correctional facilities, lost workdays for victim and perpetrator) are accounted $[3,4]$. The Centers for American Progress, in their 2012 report on "The Economic Benefits of Reducing Violent Crime," found the fiscal impacts of the specific crimes of murder; rape, assault, and robbery were over $\$ 42$ billion dollars to Americans in direct costs alone [4]. Further, as noted in their report, "Violent crimes also inflict other, more intangible costs, including the pain and suffering of victims, a reduced quality of life for everyone, and lower investment levels and property values" (p. iv). They note that the resulting fiscal impact of such indirect costs is significantly greater than that documented for the direct costs [4]. McCollister, French, and Gang [5] also found significant direct and indirect costs associated with violent crimes with murder costing approximately $\$ 9$ million dollars per event, rape/sexual assault costing approximately $\$ 240,776$ per event, and aggravated assault costing approximately $\$ 107,020$ per event. In 2010 , the United States spent approximately $\$ 261$ billion in direct costs for correctional services, police protection, legal services and judicial services [6]. When combined with "pain and suffering," and "reduced quality of life," as consistently documented in business reports, the costs have averaged approximately $\$ 450$ billion yearly over the last fifteen years, with 
violent crime accounting for approximately $\$ 426$ billion of that total $[4,7]$. Further, most of the inmates responsible for the staggering costs of violence have a documented juvenile crime record [8]. Clearly, juvenile violence is highly concerning to both the community and the healthcare system, thus necessitating better interventions and more effective prevention programs.

\section{Risk Factors for Juvenile Crimes and Recidivism}

According to the Florida Department of Juvenile Justice [9], it was determined that during the time and at the geographic location of this study, 371 juveniles were at high risk to re-offend while 497 were moderate high risk and 484 were moderate risk to re-offend. A range of factors exist that increase juveniles risk of committing a violent crime. Studies examining the mental health concerns of juvenile offenders have suggested that between $50 \%$ and $70 \%$ meet diagnostic criteria for a mental illness [10,11]. Mulder, Brand, Bullens, and Van Marle [12] found that family problems, psychopathology, and antisocial behavior during treatment all contributed to increased rates of recidivism for juvenile offenders. Environmental risk factors, such as access to firearms, may also place adolescents at increased risk for both offending and victimization [13]. Other risk factors include social contextual factors (i.e., limited social support system, rejection from peers, etc.) [14], prior criminal history [15], low academic achievement [16], cognitive ability [17], substance use [18] and historical factors (i.e., childhood maltreatment, family members with criminal histories, etc.) [15].

\section{Interventions}

The literature clearly documents a myriad of juvenile violence intervention strategies that involve community-based programs, school-based interventions, and after-school programs designed to prevent and reduce juvenile delinquency and recidivism [19]. More recently, hospital-based programs have begun to address the issue of adolescent violence. Published reports from these programs suggest an increasing appreciation of the link between youth violence and healthcare costs [20-28]. Such programs include those that identify at-risk youth based upon histories of victimization by repeated violent acts and provide intensive psychosocial follow-up to decrease recidivism [21]. Other programs intervene with adolescents who have been identified as "at risk" for membership with various gangs, exposing them to potential physical consequences of such involvement via gang violence scenarios depicted in the emergency department [25]. Additionally, some programs intervene with victims of interpersonal violence to provide case management for six months with evaluation of attitudinal changes and behavior changes thereafter [28]. Zun, Downey and Rosen [29] report that their case management approach has reduced self-reported re-injury resulting from repeat victimization or arrest. Zagar, Busch and Hughes [30] reported that the most effective interventions reduce recidivism by 10 to $40 \%$; therefore, interventions are important at reducing the rates of juveniles re-offending. While essential in combating adolescent violence, and undoubtedly successful in achieving effect, such studies on specific interventions often continue to reflect a methodology inclusive of self-report techniques to evaluate program efficacy, rather than to report independent objective outcomes measures of outcomes. To reduce subjective bias, objective independent measures of performance should also be included when possible to judge a program's treatment effect. The Eastern Association for the Surgery of Trauma (EAST) "Practice Management Guidelines for Violence Prevention Programs," [31] notes that most studies on youth violence interventions suffer from inadequate research design and limited longitudinal data following completion of the intervention. EAST further documents the more common use of self-report methodologies rather than objective, scientific outcomes measures as metrics of program evaluation.

\section{The Turning Point: Re-Thinking Violence (TPRV) Program}

In response to the need for intervention programs that also include an objective measure of program efficacy, we constructed a multi-dimensional, multi-agency violence intervention program for at-risk adolescents and their parents in 1999 [19] incorporating longitudinal follow-up. "Turning Point: Re-Thinking Violence," (TPRV) is a hospital-based program to address the issue of juvenile violence. TPRV program is a six-week, court-ordered program composed of four key elements: Trauma Experience (teens and parents are taken on a tour of trauma center and hospital morgue, wherein they are exposed to real-life medical interventions, explanations regarding equipment utilized and procedures performed, and the "real world" consequences of violence, including death), Victim Impact Panel (teens/parents attend a panel discussion addressing the aftermath of violence upon the family and friends of victims), Group Process (five weeks of group therapy encompassing psycho education regarding various factors involved in effective decision-making versus the choice to perpetrate a violent act), and Community Networking (individualized referral information for follow-up mental health services consistent with participant's healthcare coverage and the area in which they live) [19]. Total face-to-face contact is approximately 14 hours and is believed to strengthen the focus, structure, and efficiency of the program. Additional contact hours may be added for follow-up individual counseling, if such a need is determined. TPRV engages multiple community agencies to address the problem of adolescent violence, with the specific focus on presenting the effects of violence in a real-world context (via the Trauma Experience and the Victim Impact Panel) while arming each youth and parent with necessary strategies to cope more effectively (via group process on anger management and conflict resolution) in the frequently dangerous world in which many of these youth live [19].

The TPRV utilizes several components that have been suggested to be effective at reducing recidivism. For example, this intervention is therapeutic in nature, allowing for participants to have opportunities to process their feelings while also being provided with psycho education on communication skills, conflict resolution skills, and anger management. Lipsey [32] found in a meta-analysis of 548 studies that one of the main factors significantly correlated with larger decreases in recidivism was an intervention that has a therapeutic philosophy. Another factor found to be effective at reducing recidivism is working with high-risk offenders [32]. Given that this intervention solely works with juvenile offenders of violent crimes, TPRV targets high-risk offenders. It was also found that counseling in group formats also had lower rates of recidivism compared to individual, family, family crisis, peer, and mixed formats of counseling [32]. Likewise, skill-building interventions also demonstrated decreases in recidivism [32]. TPRV is conducted solely in a group format and places an emphasis on building skills in communication and conflict resolution. In another meta-analysis of 39 studies, it was found that behavioral-oriented programs had the largest effects [33]. Moreover, it was beneficial for programs to be multi-modal and have a level of intensity that matches the risk of the 
juvenile to re-offend [33]. As such, TPRV incorporates these elements with the overarching goal of reducing risk of recidivism.

Since initial design and implementation in 1999, many changes and additions have been made to the TPRV core program. These have included incorporating a parent education component, consistent with the positive conflict resolution skills that are practiced with participants. This exposes parents/guardians to the same set of anger management tools, and is intended to promote subtle changes within the home environment toward adaptive coping for participants, as well as their parents and siblings. The intent also is to engender a degree of accountability and/or "buy-in" from parents/ guardians for continued positive development and personal growth among program participants.

Another addition to the program has been the use of a doctoral level psychology resident as one of the two group facilitators. Prior to this change, both group facilitators had solely criminal justice backgrounds. Using a psychology trained facilitator, we were able to better identify "deeper" individual issues that often become evident during the group process. More appropriate referrals for individual counseling beyond the TPRV program were then made possible when needed by a given participant. Given the high incidence of mental health problems identified within the juvenile justice system [34], this early identification and treatment for such issues in first-time offenders may be a deterrent for future legal problems relating to mental health disorders. In response to the most recent findings that almost one of every three juveniles referred to Florida's Department of Juvenile Justice is female [2], we have added female first-time violent crime offenders to the inclusion criteria for TPRV. However, all group sessions are same sex, so that gender issues do not detract from the group process, and the program utilizes a male and a female group facilitator.

Lastly, we have added the requirement that each program graduate write a three to five minute speech to be presented to the collective audience of family and supporters at the program graduation. We feel that preparing this speech reinforces the strategies the participants have learned and the positive lessons they choose to take with them. Participants' parents listen to the speeches, thereby enhancing the concept of accountability and buy-in on their part to promote continued adaptive coping in their child and the family unit.

Initial evaluation of the efficacy of the TPRV program as originally designed, revealed significantly lower violence recidivism rates for TPRV graduates when compared to the control group that was matched by race to participants in the study group (AUTHOR citation). The study group demonstrated an overall recidivism rate of 0.05 within the year after graduation from the TPRV program, whereas the control group experienced a recidivism rate of 0.33 . Although clearly revealing a positive treatment effect of the TPRV program on juvenile violence recidivism, limitations of this initial study have been recognized. These included the recognized need for longitudinal data to reflect sustainable treatment effects of TPRV on violence recidivism. The purpose of the present study was to evaluate the long-term effect of TPRV both in terms of violence recidivism and in evaluation of program efficiency, as indicated by maintained therapeutic effect.

\section{Method}

\section{Participants}

Participation within TRPV depended upon assignment to the treatment program amongst adjudicated teens by one of three court justices. TRPV was one of several options court justices had available, and assignment to any given option was done at random. Justices were unaware that the present study was taking place, and all juveniles within the program were participants within the study. On average, it took participants one to three months to begin the TPRV program after referral was made by a juvenile judge. This allowed for the screening process to occur before the participant was formally accepted into the program. General inclusion criteria included: first-time offenders of a violent offense (i.e., robbery, assault, battery, aggravated assault, aggravated battery, or other weapons offenses) and 11-17 years old. Additionally, all participants were screened via structured interview for appropriateness for inclusion into the TPRV program - cognitive ability to participate in the group process, no history of sexual offense or victimization, and no history of a pronounced mental health disorder requiring current, intensive treatments. Cognitive ability was informally determined by the participant's ability to engage in conversation during the screening process and their orientation to time, place, and person. There were no restrictions involving socioeconomic status or ethnic background and all participants resided in the local area, a large metropolitan city in the southeast United States.

The participants in the study group $(n=115)$ met general inclusion criteria for acceptance to the TPRV program as detailed above. Of the 115 participants, 109 (94.8\%) were male and 6 (5.2\%) were female. Participants ranged in age from 11 to 18 years with a mean age of 15.3 years at the first session they attended. Although general inclusion criteria did not include people aged 18 or older, eight participants were 17 at the time of referral but turned 18 by the time they participated in the intervention. In terms of ethnicity, $67.0 \%$ were African American $(n=77)$ and $33.0 \%(n=38)$ were Caucasian. There were no participants who reported being Hispanic/Latino, Asian/Asian American, American Indian/Alaska Native, Hawaiian Native/Pacific Islander, or Multiracial. In Table 1, the types of violent crimes committed for each participant is provided.

The 115 participants in this study were compared to an index group of 38 participants from an initial study on the TPRV program [19]. Those in the index group were comparable in demographics to the participants in this study. Of those in the index group, $100.0 \%$ $(\mathrm{n}=38)$ were male. Moreover, $63.2 \%(\mathrm{n}=24)$ were African American, $34.2 \%(n=13)$ were Caucasian, and $2.6 \%(n=1)$ was neither African American nor Caucasian. The mean age of the index group was 16.08 years. The types of violent crimes committed by those in the index group included battery $(n=22)$, aggravated battery $(n=6)$, aggravated assault $(n=6)$, and weapon possession $(n=2)$. Additionally, two juveniles in the index group committed crimes that did not fall into one of those four categories. Those in the index group were also geographically from the same area as those participants in this study.

This study was approved by the Institutional Review Board (IRB) and consistent with IRB requirements, all participants and their parents/guardians were provided with thorough explanation of the research activity and informed consent for inclusion in this study. Participation in the research component of TPRV was not required for eligibility to complete the TPRV program. 


\begin{tabular}{|c|c|c|c|}
\hline \multicolumn{2}{|r|}{ Type of Crime } & \multirow{2}{*}{$\begin{array}{c}\begin{array}{c}\text { Number of } \\
\text { Participants } \\
\text { (n=115) }\end{array} \\
4\end{array}$} & \multirow{2}{*}{$\begin{array}{c}\begin{array}{c}\text { Percentage } \\
\text { of Overall } \\
\text { Participants }\end{array} \\
3.5 \%\end{array}$} \\
\hline \multirow{2}{*}{ Assault } & Aggravated & & \\
\hline & Misdemeanor & 1 & $0.9 \%$ \\
\hline \multicolumn{2}{|c|}{ Assault and battery } & 2 & $1.7 \%$ \\
\hline \multicolumn{2}{|c|}{ Arson, 1st degree } & 1 & $0.9 \%$ \\
\hline \multirow{10}{*}{ Battery } & Aggravated & 6 & $5.2 \%$ \\
\hline & Aggravated with a deadly weapon & 4 & $3.5 \%$ \\
\hline & Domestic & 7 & $6.1 \%$ \\
\hline & Felony & 5 & $4.4 \%$ \\
\hline & Hate crime & 2 & $1.7 \%$ \\
\hline & Misdemeanor & 1 & $0.9 \%$ \\
\hline & Simple & 10 & $8.7 \%$ \\
\hline & Unspecified & 40 & $34.8 \%$ \\
\hline & $\begin{array}{l}\text { Victim was an official, school } \\
\text { employee, or school board member }\end{array}$ & 4 & $3.5 \%$ \\
\hline & Violation of probation & 1 & $0.9 \%$ \\
\hline \multirow{2}{*}{ Burglary } & Armed & 1 & $0.9 \%$ \\
\hline & Dwelling & 1 & $0.9 \%$ \\
\hline \multicolumn{2}{|c|}{ Child abuse } & 1 & $0.9 \%$ \\
\hline \multicolumn{2}{|c|}{ Criminal mischief } & 1 & $0.9 \%$ \\
\hline \multicolumn{2}{|c|}{ Drug possession, cannabis } & 3 & $2.6 \%$ \\
\hline \multicolumn{2}{|c|}{$\begin{array}{l}\text { Interference of school function, resistance } \\
\text { without violence }\end{array}$} & 1 & $0.9 \%$ \\
\hline \multicolumn{2}{|c|}{ Intoxication, disorderly } & 1 & $0.9 \%$ \\
\hline \multicolumn{2}{|c|}{ Robbery, armed } & 2 & $1.7 \%$ \\
\hline \multicolumn{2}{|c|}{ Shooting or throwing deadly missiles } & 1 & $0.9 \%$ \\
\hline \multirow{3}{*}{ Theft } & Grand & 2 & $1.7 \%$ \\
\hline & Petit & 3 & $2.6 \%$ \\
\hline & Trespassing & 3 & $2.6 \%$ \\
\hline \multirow{3}{*}{ Weapon } & Carrying concealed weapon & 2 & $1.7 \%$ \\
\hline & Possession & 3 & $2.6 \%$ \\
\hline & Possession on school property & 2 & $1.7 \%$ \\
\hline
\end{tabular}

\section{Procedure}

Table 1: Crimes committed by juvenile participants.

The dependent outcome measure "recidivism" was defined following the guidelines of the National Criminal Justice Reference Center. As detailed in the Office of Juvenile Justice and Delinquency report, "Juvenile Offenders and Victims: 2006 National Report," [35] recidivism is criminal behavior that is repeated. However, "a recidivism rate may reflect any number of possible measures of repeated offending - arrest, court referral, conviction, correctional commitment, and correctional status changes within a given period of time." For this study, we operationalized recidivism as the juvenile being arrested and adjudicated in order to thoroughly evaluate program efficacy. Representatives from the Division of Juvenile Justice, State Attorney's Office, extracted all recidivism data from the formal records in the juvenile and adult justice management information systems. These systems contain the records of all juveniles and adults formally entered into the justice system. Both systems were utilized, as many of the participants in our pool reached the age of 18 years at some point during our study period and, thus, entered the adult system. Recidivism rates were examined one year following the initial violent offense. According to the Florida
Department of Juvenile Justice [36], the average juvenile offender will re-offend within five months of completion of their sentence-related service; therefore, a one year recidivism rate is inclusive of the time most likely a juvenile will re-offend for this geographical area.

Initially, all consenting participants entered into this study from the program's inception $(n=115)$ and participated in the 14-hour TPRV program over the course of six sessions. A session-by-session description of the TPRV program is provided in Table 2. Following graduation from the TPRV program, the participants were evaluated for violence recidivism by studying any subsequent conviction for a second violent offense. Recidivism within this group was then compared to the initial cohort sentenced to the "traditional" 100 hours community service (e.g., the index group), as reported in the initial study [19]. Secondly, all participants were studied as individual cohorts, stratified by year of program entry, and were compared across cohorts. Finally, within annual cohorts, we studied timing of violence recidivism in relation to program graduation (intervention).

\section{Results}

For the seven-year duration of TPRV, the violence recidivism rate still remains significantly below that which was reported in the index group from the initial TPRV study [19]. In that index group, as reported in Scott et al., [37] the TPRV study group had an overall recidivism rate of 0.05 as compared to the 0.33 recidivism rate of the control group (matched to the study participants by race) revealed a recidivism rate of $0.33, p<0.05$. The violence recidivism rate in this current study is 0.09 for all participants collectively over six years of program implementation.

Stratified annual analysis demonstrates a statistically significant decrease in violence recidivism as TPRV has evolved. (Table 3) Additionally, time line analysis of incidence of violence recidivism, in relation to program graduation, indicates the highest likelihood of violence recidivism is in the first year following program completion, and with decreased incidence thereafter (refer to table 3).

\section{Discussion}

These data suggest that this 14-hour program of juvenile violence intervention and education is a more effective sanction than the established sentencing options for first-time violent adolescent offenders (e.g., community service hours or probation). Given that first-time juvenile offenders often re-offend within one year of the first offense [38], this intervention implemented within a few months of the juvenile's first offense is timely to help prevent recidivism. The standardized, "core" program content and components (Trauma Experience, Victim Impact Panel, Group Process and Community Networking) appear to be significantly more effective in deterring future violence than merely punitive sanctions alone. By using violence recidivism as the outcome measure, we have maintained an objective, outcome study of treatment effect. Comparison of the overall recidivism rate for our program graduates to published violence recidivism rates for similar first-time offenders who received "standard court sentencing options" suggest that TPRV is more effective in reducing recidivism [39]. Moreover, our recidivism rate of 0.09 is significantly lower than the initial cohort control rate of 0.33 , as well as to this similar study group whose recidivism rate was 0.38 [39].

These data do reveal a variant that requires explanation. As seen in Table 3, no participants were enrolled in Year 2, and only nine participants in Year 3 were enrolled, two of which re-offended resulting in the recidivism rate of 0.22 , as shown. During this time 
Citation: Scott KK, Canto AI, Smith SM, Tepas JJ (2014) Turning Point-Rethinking Violence: A Youth Violence Reduction Intervention. J Emerg Med Trauma Surg Care 2: 004.

- Page 5 of 8 -

\begin{tabular}{|c|c|c|c|c|}
\hline $\begin{array}{l}\text { Session } \\
\text { Number }\end{array}$ & Session Title & Session Goal(s) & Session Activities & Attendees \\
\hline 1 & Trauma Experience & $\begin{array}{l}\text { Gain understanding of the consequences of } \\
\text { violence }\end{array}$ & $\begin{array}{l}\text { - Tour of the Level } 1 \text { trauma center, morgue } \\
\text { and autopsy room of the hospital } \\
\text { - Discussion with a trauma surgeon } \\
\text { - Watch the video "Crime and Consequences" }\end{array}$ & $\begin{array}{l}\text { Juvenile Participants, } \\
\text { Parent(s) of Juvenile }\end{array}$ \\
\hline 2 & Group Process & $\begin{array}{l}\text { - Develop reality-based communication skills } \\
\text { - Process feelings related to violence } \\
\text { - Establish rapport and trust among the group }\end{array}$ & $\begin{array}{l}\text { - Group therapy session with psycho education } \\
\text { on reality-based communication skills } \\
\text { - Group members have the ability to process } \\
\text { their feelings }\end{array}$ & Juvenile Participants \\
\hline 3 & Victim Advocate Panel & $\begin{array}{l}\text { Gain further understanding of the consequences } \\
\text { of violence }\end{array}$ & $\begin{array}{l}\text { Friends and family members who have lost } \\
\text { someone to violent acts share their stories } \\
\text { about the consequences of violence }\end{array}$ & $\begin{array}{l}\text { Juvenile Participants, } \\
\text { Parent(s) of Juveniles }\end{array}$ \\
\hline 4 & Conflict Resolution I & Develop conflict resolution skills & $\begin{array}{l}\text { - Group facilitators model conflict resolution } \\
\text { skills } \\
\text { - Juvenile participants engage in role-plays to } \\
\text { practice conflict resolution skills }\end{array}$ & Juvenile Participants \\
\hline 6 & Graduation & $\begin{array}{l}\text { - Recognize personal growth } \\
\text { - Encourage networking within the community }\end{array}$ & $\begin{array}{l}\text { - Presentation of graduation certificates } \\
\text { - Juvenile participants read their own speeches } \\
\text { - Participants are provided with individualized } \\
\text { referrals to mental health resources }\end{array}$ & $\begin{array}{l}\text { Juvenile Participants, } \\
\text { Parent(s) of Juvenile, Other } \\
\text { People Invited by Juvenile }\end{array}$ \\
\hline
\end{tabular}

Table 2: Session by Session Description of TPRV Program.

\begin{tabular}{|c|c|c|c|c|c|c|}
\hline Year Graduated from TPRV & $\mathbf{n}$ & 1 Yr. Post-Grad. & 2 Yrs. Post-Grad. & 3 Yrs. Post-Grad. & 4 Yrs. Post-Grad. & 5 Yrs. Post-Grad. \\
\hline Year 1 & 35 & 0.05 & 0.05 & 0.09 & 0.05 & 0.02 \\
\hline Year 2 & 0 & - & - & - & - & - \\
\hline Year 3 & 9 & 0.22 & 0.00 & 0.00 & 0.00 & \\
\hline Year 4 & 21 & 0.04 & 0.00 & 0.00 & & \\
\hline Year 5 & 19 & 0.09 & 0.00 & & & \\
\hline Year 6 & 11 & 0.00 & & & & \\
\hline Year 7 & 20 & 0.00 & & & & \\
\hline
\end{tabular}

Table 3: Rates of violence recidivism for all participants over time.

Note: The TPRV Program did not enroll participants during Year 2. All rates for recidivism represent offenses made by two repeat offenders, each with multiple re-offenses.

period, the TPRV program had hired an interim Program Coordinator who also functioned as one of the two group facilitators; this person had a criminal justice background and was employed full-time by the Division of Juvenile Justice. In Year 4, a doctoral-level psychology resident was hired and took over both of these responsibilities. The addition of this key mental health component appeared to have a positive treatment effect. We believe that the positive effect of the addition of the psychology resident was likely due to the amount of specialized training and education received by this person; however, factors such as interpersonal style and personality could have also contributed to the effect. The addition of the psychology resident was not experimentally explored, however, so interpretations about the effects of this addition should be taken with caution.

From the outcomes data, it also appears that the treatment effect of TPRV is sustained longitudinally, as revealed in the decreased violence recidivism over time elapsed from program completion. Additionally, it appears the efficacy of the TPRV program has improved; possibly as a result of the continued program revisions based primarily upon feedback solicited from participants and their families as well as the feedback from the program facilitators. Thus, the program appears to be a successful strategy for decreasing violence of participants. Notably, all but two participants who did re-offend did so only once in the span evaluated. The two "outliers" accounted for the repeated offenses over each subsequent year following graduation from the program. These two juveniles had graduated from the TPRV program in its first year of implementation.

It appears that the continued evolution of the TPRV program is generating a more focused and effective impact on program graduates compared to controls and to previous cohort graduates. In comparison to previous literature on empirically supported or evidence-based interventions, we believe that there are several key factors that contribute to the success of TPRV in reducing participant recidivism. In 2005, the Florida Department of Juvenile Justice presented a report, "What Works: A Vision for Florida's Juvenile Justice System" [40]. In that report, programs that were identified as successful incorporated "behavioral treatments," such as our cognitive behavioral approach; "family centered treatments," as we include parents/guardians in the overall intervention plan; and "modeling and mentoring," which we achieve by role-playing with participants, modeling appropriate behaviors and interventions for parents/ guardians, and one-on-one mentoring through positive relationships developed between participants and the group facilitators. Many of these youths lack positive role models; both adult and peer adaptive social relationships are sorely lacking. The focus on honesty and the strengths of each may encourage each participant to set a higher 
standard for themselves in relation to not only their own behaviors, but also the behaviors of those in their social network.

A report from a similar program in Virginia emphasized that the most effective programs have common characteristics, which include incorporating checks for treatment integrity and the use of personnel trained in mental health to facilitate the intervention [41]. The doctoral resident has been trained in the importance of treatment fidelity, empirically supported mental health interventions, and group counseling process. The utilization of the doctoral level psychology resident as one of our group facilitators is a possible factor promoting the program's enhanced effect. This supports the view that employment of a mental health professional, rather than criminal justice personnel, promotes a more favorable outcome within violence intervention programs.

Finally, the addition of the required graduation speech appears consistent with other interventions that have been proven effective. Specifically, "Project Back-on-Track," utilizes a graduation ceremony that includes participant recitation of individual skills learned in Project Back-on-Track, along with presentation of graduation certificates, etc., as done in our program [42]. From the initial inception of TPRV, we have felt a formal graduation ceremony was critical to recognizing the personal growth made during the program's duration and highlighting the positive outcomes of successful program completion for each graduate and their families.

Another factor key to the continuation of the TPRV program is the community support and multi-agency approach we take to violence intervention. Panelists comprising the Victim Impact Panel routinely participate in our groups by describing the effects of having lost a loved one to violence. The relationships forged with these panelists have promoted our involvement in other community initiatives such as "Mental Health for Youthful Offenders," a program developed to address the mental health needs of incarcerated adolescents, and our participation with the city-wide Victims Advocacy programs. Additionally, the strong and positive relationships we have developed with the State Attorney's Office and the Department of Juvenile Justice have resulted in our trauma program's participation in other key initiatives such as, "F.A.C.E. the Violence," a one-day program we developed in partnership with the local sheriff's office, the trauma hospital, and local church leaders to educate the community about the negative effects of violence personally, community-wide, and to society. F.A.C.E., "Families and Citizens Empowered," again linked the medical, community, and legal systems together for a common need: violence reduction.

As a result of the positive relationships between our trauma program and the State Attorney's Office, Juvenile Division and the overall success of the program, funding has been available thus far for TPRV. When we have been unable to achieve grant support through our own efforts, the State Attorney's Office has worked diligently to secure local funding resources such that the program may continue. This further encourages our team to improve and enhance our program to achieve its greatest effect.

\section{Limitations}

While this study does answer questions regarding the sustainability of the treatment effect over time, it is limited by the use of recidivism as the sole outcomes measure. Violence recidivism is an objective measure of treatment effect; however, one cannot minimize the importance of other aspects of the TPRV program that promote the program's success. Unfortunately, we have been unsuccessful in retrieving data regarding the actual utility of the mental health referral that is provided to each participant at the conclusion of the program. In future research on this program we will include a follow-up questionnaire at one-year post-program completion requesting feedback on various aspects of the program. This could include whether the mental health referral was utilized as well as how parents/guardians perceived behavioral changes in their child over time (e.g., attitude, use of conflict resolution skills in the home setting, impact on siblings and extended family, etc). A limitation in that strategy, however, is the transiency of many of the participants in the local area. We do know from narrative feedback we have received thus far, that parents appear to recognize the positive impact of our program, as they have frequently requested other children in the family and extended family members be allowed to participate in the program without court order. Unfortunately, we are unable to facilitate such participation, as we feel the first-time offender groups have a different dynamic than those youth who have not been formally "introduced" to the juvenile justice system through their behaviors.

Another limitation of this study is that a randomized control trial design was not utilized. Although those who participated in the TPRV program were compared to an index group similar in demographics, a randomized control trial would have allowed us to have more confidence in our results and would have reduced possible threats to validity (e.g., history). Additional statistical analyses, such as Cox Regression, may have been helpful to provide additional support and information regarding the effectiveness of this intervention. As a result of not using a randomized control trial design and additional statistics, the results of this study should be interpreted with caution and future studies are needed to demonstrate the positive impact of the TPRV program. Moreover, additional confidence could have been placed in the results had we used a current comparison group rather than an index group. In future research on program effectiveness, it is also ideal to consider participants' criminal history as a control variable; however, all participants in the present study were first time offenders of a violent crime. As such, it is believed that matching and controlling by race was appropriate. Lastly, we were unable to compare the different components of the intervention to determine what parts were most helpful to the participants. Future research may examine the different components to determine which intervention components individually or in tandem are most effective at reducing recidivism.

\section{Research Implications}

Future directions for program enhancements include increasing the number of female groups in response to rising female offenders and developing a "TPRV Diversion Program," patterned after the present program, but aimed toward youth prior to actual adjudication for a violent offense. Such youth will likely comprise a younger subject pool requiring modification of the curriculum to be developmentally appropriate for those participants. However, as recent data on juvenile offending suggests, adolescents are engaging in violent acts at younger ages - interventions necessarily should likewise begin sooner. Another addition to our program will be to enhance the recognition of the co-morbidity between violence and alcohol/drug abuse. While we looked at violence recidivism only, it would be interesting to review any subsequent offenses such as non-violent crimes affiliated with substance abuse.

Additional considerations for future research on this program or the development of similar programs include adding measures of 
individual mental health progress. For example, we suspect that participants' self-esteem may be increasing over the course of the program as evidenced by changes in the types of statements they make and how they carry themselves within group and individually with the group facilitators. It would be interesting to add measures of self-esteem to determine if, in fact, the program has any effects in that area also. Similarly, we have observed that most participants often begin the program with an oppositional air and conclude the program working pro-actively with peers. This would need to be empirically investigated, perhaps with using measures of peer attachment or pro-social behaviors. Lastly, it would be helpful for future studies to examine changes based on types of offenses and subgroups of offenders who participate in TPRV, as it has been suggested that recidivism rates may differ depending on the nature of the crime [43].

\section{Clinical and Policy Implications}

One additional consideration of TPRV should include expansion of the program referral sources to include medical treatment teams within hospital Emergency Departments and/or Trauma Centers. The literature clearly documents the high incidence of hospital admissions among adolescents due to violence. As many of the very perpetrators of violent acts likely become a victim of violence themselves, there appears a "golden opportunity" for hospital treatment teams to address the violence beyond simply treating the wounds. A potential future direction for TPRV will be development of a Diversion arm of the program. This Diversion TPRV could accept referrals from medical treatment teams who identify at-risk teens based upon their mechanisms of injury and information obtained from the injured teens and/or their parents on initial examination. Development of a brief screening tool could further aid in effective screening and identification of at-risk youth. As TPRV has been shown to decrease violence recidivism, this expansion of the referral base to include medical treatment teams could, in turn, have a direct fiscal impact on hospital systems by decreasing hospital admissions and resource utilization secondary to violence.

\section{Conclusion}

In summary, we are encouraged by the apparent success of TPRV, and by the growth in number and types of violence intervention programs that are affiliated with trauma and emergency department programs. The inherent link between trauma care and violence reduction is rapidly emerging as a major public health issue. The facts speak for themselves regarding the financial cost of violence. As this cost is better defined in personal quality of life and escalating societal burden, we anticipate that alliances with the legal and social support systems, such as the ones we have described, will become increasingly critical as effective tools for understanding, controlling, and eventually eliminating the epidemic of adolescent violence. It is important to note, however, that the operational definitions of victim and perpetrator are sometimes ill-defined in cases when it is unclear who started the violence but multiple parties participated and were arrested - a caution identified by Peterson in a report by Cooper and colleagues [21]. This can complicate both future research and public policy initiatives.

Without doubt, multi-agency, cooperative programs that address youth violence can be successful in decreasing violence recidivism. Such alliances also have the ability to take interventions to the next level, by viewing adolescent violence as a public health epidemic and utilizing their collective "voice" to advocate for future programming efforts and public policy developments geared towards continued violence reduction. As is eloquently summarized by Cunningham et al. [23], "Advocating for evidence-based policy change complements the importance of advocating for individual patients. It enables us to work upstream to prevent or minimize the high-risk environments that placed patients in our care in the first place." (p. 496). Indeed, adopting collaborative intervention programs such as Turning Point: Re-Thinking Violence, which can be replicated in other communities, will expand the outcomes data pool such that this objective, evidence-based practice will stand as not only a viable fiscal alternative to standard sentencing options, but also a constructive, successful strategy in ameliorating the public health epidemic that is youth violence.

\section{Acknowledgement}

The authors would like to acknowledge and thank the City of Jacksonville, State Attorney's office for their ongoing collaboration and support with this project. This study was supported in part by grants from The Jacksonville Jaguars Foundation, The Blue Foundation for a Healthy Florida, and the City of Jacksonville, FL. The authors would also like to acknowledge Christopher Brooks for his dedication to program co-facilitation throughout the history of the program.

\section{References}

1. Federal Bureau of Investigations (2012) Crime in the United States 2012.

2. Florida Department of Juvenile Justice (2012) Five year trends and conditions.

3. Anderson DA (2011) The cost of crime. Foundations and Trends in Microeconomics 7: 209-265.

4. Shapiro RJ, Hassett KA (2012) The economic benefits of reducing violent crime: A case study of 8 American cities. Report from the Center for American Progress: Doing What Works.

5. McCollister KE, French MT, Fang H (2010) The cost of crime to society: new crime-specific estimates for policy and program evaluation. Drug Alcohol Depend 108: 98-109.

6. Kyckelhahn T, Martin T (2013) Justice expenditure and employment extracts, 2010-preliminary. Bureau of Justice Statistics Clearinghouse: Rockville, MD, USA.

7. Investor's Business Daily (1996) Perspective: Crime's cost. National Center for Policy Analysis. p: B-1.

8. Dilulio JJ, Mitchell GA (2006) Who really goes to prison in Wisconsin? A profile of urban inmates in Wisconsin prisons.

9. Florida Department of Juvenile Justice (2014a) Delinquency profile 20122013: PACT risk to re-offend - youth received circuit 4 Duval county.

10. Fazel S, Doll H, Långström N (2008) Mental disorders among adolescents in juvenile detention and correctional facilities: a systematic review and metaregression analysis of 25 surveys. J Am Acad Child Adolesc Psychiatry 47: 1010-1019.

11. Teplin LA, Abram KM, McClelland GM, Dulcan MK, Mericle AA (2002) Psychiatric disorders in youth in juvenile detention. Arch Gen Psychiatry 59: 1133-1143

12. Mulder E, Brand E, Bullens R, Van Marle H (2010a) A classification of risk factors in serious juvenile offenders and the relation between patterns of risk factors and recidivism. Crim Behav Ment Health 20: 23-38.

13. Ruback RB, Shaffer JN, Clark VA (2011) Easy access to firearms: juveniles' risks for violent offending and violent victimization. J Interpers Violence 26 : 2111-2138.

14. Kubrin CE, Stewart EA (2006) Predicting who reoffends, the neglected role of neighborhood context in recidivism studies. Criminology 44: 165-197. 
Citation: Scott KK, Canto AI, Smith SM, Tepas JJ (2014) Turning Point-Rethinking Violence: A Youth Violence Reduction Intervention. J Emerg Med Trauma Surg Care 2: 004.

15. Mulder E, Brand E, Bullens R, van Marle H (2010b) Risk factors for overall recidivism and severity of recidivism in serious juvenile offenders. International Journal of Offender Therapy and Comparative Criminology 55: 118-135.

16. Christle CA, Jolivette K, Nelson M (2005) Breaking the school to prison pipeline: Identifying school risk and protective factors for youth delinquency. Exceptionality: A Special Education Journal 13: 69-88.

17. Vermeiren R, Schwab-Stone M, Ruchkin V, De Clippele A, Deboutte D (2002) Predicting recidivism in delinquent adolescents from psychological and psychiatric assessment. Compr Psychiatry 43: 142-149.

18. Ford JA (2005) Substance use, the social bond and delinquency. Social Inquiry 75: 109-127.

19. Park-Higgerson HK, Perumean-Chaney SE, Bartolucci AA, Grimley DM, Singh KP (2008) The evaluation of school-based violence prevention programs: a meta-analysis. J Sch Health 78: 465-479.

20. Cheng TL, Schwarz D, Brenner RA, Wright JL, Fields CB (2003) Adolescent assault injury: risk and protective factors and locations of contact for intervention. Pediatrics 112: 931-938.

21. Cooper C, Eslinger DM, Stolley PD (2006) Hospital-based violence intervention programs work. J Trauma 61: 534-537.

22. Corbin TJ, Rich JA, Bloom SL, Delgado D, Rich LJ, et al. (2011) Developing a trauma-informed, emergency department-based intervention for victims of urban violence. J Trauma Dissociation 12: 510-525.

23. Cunningham R, Knox L, Fein J, Harrison S, Frisch K, et al. (2009) Before and after the trauma bay: the prevention of violent injury among youth. Ann Emerg Med 53: 490-500.

24. Cunningham RM, Vaidya RS, Walton M, Maio RF (2005) Training emergency medicine nurses and physicians in youth violence prevention. Am J Prev Med 29: $220-225$.

25. Hughes KM, Griner D, Guarino M, Drabik-Medeiros B, Williams K (2012) A Second's Chance: Gang Violence Task Force prevention program. Am Surg 78: 89-93.

26. Sidelinger DE, Guerrero AP, Rodríguez-Frau M, Mirabal-Colón B (2005) Training healthcare professionals in youth violence prevention: an overview. Am J Prev Med 29: 200-205.

27. Snider CE, Nathens AB (2010) Where should we implement emergency department secondary prevention programs for youth injured by violence? J Trauma 69: 991-994.

28. Zun LS, Downey L, Rosen J (2004) An emergency department-based program to change attitudes of youth toward violence. J Emerg Med 26: 247-251.
29. Zun LS, Downey L, Rosen J (2006) The effectiveness of an ED-based violence prevention program. Am J Emerg Med 24: 8-13.

30. Zagar RJ, Busch KG, Hughes JR (2009) Empirical risk factors for delinquency and best treatments: where do we go from here? Psychol Rep 104: 279-308.

31. Eastern Association for the Surgery of Trauma (1998) Practice management guidelines for violence prevention programs, USA.

32. Lipsey MW (2009) Primary Factors that Characterize Effective Interventions with Juvenile Offenders: A Meta-Analytic Overview. Victims \& OffendersVictims \& Offenders 4: 124-147.

33. de Vries SL, Hoeve M, Assink M, Stams GJ, Asscher JJ (2014) Practitioner review: Effective ingredients of prevention programs for youth at risk of persistent juvenile delinquency - recommendations for clinical practice. J Child Psychol Psychiatry 12320.

34. Pullmann MD, Kerbs J, Koroloff N, Veach-White E, Gaylor R, et al. (2006) Juvenile offenders with mental health needs: reducing recidivism using wraparound. Crime \& Delinquency 52: 375-397.

35. US Department of Justice (2006) Juvenile offenders and victims: 2006 national report, US Department of Justice, Office of Juvenile Justice 234-235.

36. Florida Department of Juvenile Justice (2014) Recidivism time to failure.

37. Scott K, Tepas J, Frykberg E, Taylor P, Plotkin A (2002) Turning point: rethinking violence- valuation of program efficacy in reducing adolescent violent crime recidivism. J Trauma 53: 21-27.

38. Shapiro CJ, Smith BH, Malone PS, Collaro AL (2010) Natural experiment in deviant peer exposure and youth recidivism. J Clin Child Adolesc Psychol 39: 242-251.

39. Shichor D, Sechrest DK (2006) Juvenile repeat felons: examination of existing sentencing practices in California, USA.

40. Florida Department of Juvenile Justice (2005) What works: A vision for Florida's juvenile justice system.

41. Cornell DG (1999) What works in youth violence prevention. In: Cornell D, Loper A, Atkinson A, Sheras P (eds.). Youth Violence Prevention in Virginia: A Needs Assessment. VA: Virginia Youth Violence Project, Charlottesville, USA.

42. Myers WC, Burton PR, Sanders PD, Donat KM, Cheney J et al. (2000) Project back-on-track at 1 year: A delinquency treatment program for early-career juvenile offenders. J Am Acad Child Adolesc Psychiatry 39: 1127-1134.

43. Mulder E, Vermunt J, Brand E, Bullens R, van Marle H (2012) Recidivism in subgroups of serious juvenile offenders: Different profiles, different risks? Crim Behav Ment Health 22: 122-135. 